\title{
XVIII. Note on continuous-current transformers
}

\section{Professor Silvanus P. Thompson}

To cite this article: Professor Silvanus P. Thompson (1888) XVIII. Note on continuouscurrent transformers, Philosophical Magazine Series 5, 26:159, 157-162, DOI: 10.1080/14786448808628249

To link to this article: http://dx.doi.org/10.1080/14786448808628249

曲 Published online: 29 Apr 2009.

Submit your article to this journal

Џ Article views: 6

Q View related articles $\sqsubset$ 
curiously enough there is nothing said in the description of the air-thermometer by Kohlmusch as to determination of the boiling-point, the "ice point" merely being determined. An experimental determination of each point is, however, absolutely essential.

\section{Addition, June 5, 1888.}

Shortly after the reading of the foregoing paper, I commenced to use the coal-gas oxygen blowpipe-employing Fletcher's oxygen blowpipe and oxygen supplied in steel cylinders by the Scotch and Irish Oxygen Company (Brin Process). For convenience these cylinders, with the automatic apparatus supplied by the company for reducing the presicure of the gas, leave nothing to be desired; and the use of the oxygen blowpipe makes easy and simple many operations which were formerly all but impossible. In particular, the working of Bohemian tubing becomes, without the slightest exaggeration, as easy as that of common flint or soft German glass; and in addition it is a perfectly simple matter to make a junction between flint glass and Bohemian glass-tubing (Bohemian glass does not join well with soft German tubing). Another great advantage in the use of oxygen with the Bohemian glass is, that the glass does not become porcelainised when worked with this flame, as it does when worked with the ordinary flame.

With this new power to assist I have now abandoned completely the form of gauge shown in fig. 3, and instead I am using a gatuge in which the main part is made of flint glass (stop-cocks of Bohemian glass cannot, so far as I know, be procured), but in which the air-bulb $a$ and capillary tube $c$ are made of Bohemian glass, and the two glasses joined togetber a little below the bend at the top of the tube $d d$. I have not yet been able to obtain from any of the first-class makers of Bohemian tube a supply of fine capillary tubes, but these I make for myself by fusing up a piece of thick wide Bohemian tubing and drawing it down.

XVIII. Note on Continuous-current Transformers. By Professor Silvanus P. Thompson*.

T has often been proposed to distribute electric energy 1 from central stations to local distributing stations by means of transformers, which receive small currents at high potential and transform them into large currents at low

* Communicated by the Physical Suciety: read June 23, 1888. 
potential. When alternating currents are employed, inductioncoils of appropriate construction are used as transformers. But the use of such currents is attended by two disadvantages: namely, that alternate currents cannot be used for electrochemical purposes, and that, pending the invention of a satisfactory alternate-current motor, they cannot be used for the actuating motive machinery. When continuous currents are used, the appropriate transformer may be one of two types - (1) the motor-generator, (2) the commuting-transformer.

The motor-generator in its primitive form consists of a motor to receive the incoming current, geared mechanically to a generator which produces the outgoing current. A more specialized form consists of a single machine with one fieldmagnet and two armatures; one to receive the primary current, the other to generate the out-going or secondary current. If the two sets of armature-windings are coiled around the same core, each set of windings being furnished with an appropriate commutator and collecting-brushes, the development has reached its extreme case, the only remaining point being the proper method of excitation of the fieldmagnet.

The commuting-transformer is a more complex apparatus, and has been much misunderstood. It does not necessarily involve any greater amount of sparking than any ordinary dynamo. The general principle of this species of transformer may be explained by reference to a particular type. Suppose that an armature double-wound with a primary coil to receive the incoming current, and a secondary coil to generate the outgoing current, have been provided as in the previous case, each coil having its appropriate commutator. To enable this piece of apparatus to transform the currents, it must either be allowed to rotate in a magnetic field between the poles of a field-magnet, or else the field-magnet (and collecting-brushes) must be arranged to rotate, in the opposite sense, around it. But there is a third possible arrangement, namely to rotate around it the magnetic polarity while itself remains fixed. This may be done either by rotating the brushes which bring in the primary current, the magnetic circuit being completed by a mass of iron external to the ring, or by rotating also the polarity of a fixed field-magnet constructed specially for this purpose. An external fixed ring of Cramme or Pacinotti pattern, provided with a commutator, will answer for this purpose, the current being supplied by a pair of brushes which is rotated. In such a machine obviously all the parts are stationary save the revolving brushes, which must be driven by some mechanical device. Various modifications of this idea have from time to time been suggested. 
The theory of alternate current-transformers has heen investigated by various authorities. It was first shown by Maxwell that where there is mutual induction hetween two circuits, the effect upon the secondary circuit of the prosence of the primary circuit is threefold:-(a) to transform in a certain ratio the electromotive force; (b) to add to the resistance of the secondary circuit an apparent resistance equal to that of the primary multiplied by the square of the same ratio: (c) to deduct from the coefficient of self-induction of the secondary circuit a quantity equal to the coefficient of selfinduction of the primary cirenit multiplied by the square of the same ratio. The ratio in question was found to bo the quantity

$$
\frac{2 \pi n \mathrm{M}}{\sqrt{4} \pi^{2} n^{2} \mathrm{~L}_{1}{ }^{2}+\mathrm{R}_{1}^{2}} ;
$$

where $M$ is the coefficient of mutual inluction, $n$ the number of alternations per second, $L_{1}$ and $R_{1}$ the coefticient of selfinduction and the resistance respectively of the primary circuit. In a communication made last year to this Society I showed how, assuming the proper conditions of grod eonstruction to have been observed, this ratio was equal to the ratio of the number of secondary windings to the number of primary windings in the tranfformer; which ratio is known as the "coefficient of transformation."

The object of the present paper is to show that in continuous current-transformers effects of the same kind exist. The investigation is of an elementary character, secondary reactions being assumed to be negligibly small.

Consider a motor-generator, with double-wound armature of ring or drum type, arranged to rotate between the poles of a common fixed field-magnet. The magnetism of the litter may be considered for present purpose constant : the effect of variation in the magnetization will be afterwards considered. Let the number of armature-conductors of the primary or motor part, as counted all round the periphery, be called $\mathrm{C}_{1}$, and that of the secondary part be called $\mathrm{C}_{2}$. The ratio of $\mathrm{C}_{2}$ to $\mathrm{C}_{1}$ we may call the coefficient of transformation, and we shall use $k$ as the symbol of this ratio.

Now let $i_{1}, r_{1}$, and $\mathrm{E}_{1}$ stand respectively for the current, the resistance, and the induced electromotive force in the coils of the primary armature, and $i_{2}, r_{2}, \mathrm{~F}_{2}$ for the corresponding quantities for the coils of the secondary armatnre. Write $\mathrm{N}$ for the whole number of magnetic lines passing through the armature-core. Also write $e_{1}$ and $e_{2}$ for the respective differences of potential at the terminals of the primary and secondary parts. 
We shall then have

whence

$$
\begin{aligned}
& \mathrm{E}_{1}=n \mathrm{U}_{1} \mathrm{~N} \cdot 10^{-8}, \\
& \mathrm{E}_{2}=n \mathrm{C}_{2} \mathrm{~N} \cdot 10^{-8} ;
\end{aligned}
$$

$$
\mathrm{E}_{2} / \mathrm{E}_{1}=\mathrm{C}_{2} / \mathrm{C}_{1}=k \text {, }
$$

whatever the values of speed and field may be. Further,

whence

$$
\begin{aligned}
& \mathrm{E}_{1}=e_{1}-r_{1} i_{1}, \\
& \mathrm{E}_{2}=e_{2}+r_{2} i_{2} ;
\end{aligned}
$$

$$
e_{2}=k e_{1}-r_{2} i_{2}-k r_{1} i_{1} \text {. }
$$

Now assume that the work wasted in the armature in mechanical and magnetic friction, and in producing eddy-currents, is negligibly small compared with the work done in driving the generator part. This is, in fact, merely assuming that the machine is properly designed and constructed ; for in such machines, there being no driving-belt, the only forces except gravity are centrally balanced, and mechanical friction at the bearings is a minimum ; and further, if the iron core is of proper quality and quantity, and properly laminated and insulated, the losses due to hysteresis and eddy-currents are very small*. We shall then have the work $\mathrm{E}_{1} i_{1}$ done by the primary current (in unit time) equal to the work $\mathrm{E}_{2} i_{2}$ done on the secondary current. Consequently $i_{1}=k i_{2}$. Inserting this value, we at once get

$$
e_{2}=k e_{1}-\left(r_{2}+k^{2} r_{1}\right) i_{2} \text {. }
$$

This shows that everything goes on in the secondary circuit as though the induced electromotive force was transformed from the difference of potentials at the terminals of the primary circuit in proportion to the respective numbers of windings on the armature, and as though there were then added to the real internal resistance of the secondary circuit a resistance equal to that of the primary winding multiplied by the square of the coefficient of transformation. If there are equal weights of copper in the primary and secondary windings, the actual resistances of the two windings will be proportional to the squares of the numbers of turns : hence the effect of multiplying $r_{1}$ by $k^{2}$ is to make it equal to $r_{2}$; in other words, the added virtual resistance is equal to the real internal resistance.

* If $F$ be the waste work done against mechanical and magnetic friction, the formula becomes

$$
e_{2}=k e_{1}-i_{2}\left(r_{2}+k^{2} r_{1}+\mathrm{F} / i_{2}^{2}\right)
$$


With respect to self-induction and its effects in such machines, it may be remembered that, in an ordinary singlewound dynamo, the effect of self-induction is to add to the armature a spurious resistance, owing to the successive stoppage and restarting twice in every revolution of the current in each section. Now if matters were so arranged in the double-wound machine that commutation of the current in any one section of the primary should occur exactly at tho same instant as commutation of the current in that section of the secondary wire which was wound over the same part of the common core, it is clear that, as the currents in tho primary and secondary circulate around the core in opposite senses, the stopping of the current in the one would tend to stop the (inverse) current in the other, and the starting again of the current in the one would tend to start the inverse current in the other. In other words, the mutual induction between the two sections would tend to counteract in both the effects of self-induction. In practice it is impossible to fully realize this neutralizing effect; but that it is very nearly realized is evidenced by the almost complete absence of sparking in such machines.

In the above argument it has been assumed that the magnetism of the field-magnet was constant in amount; but incidentally it was noticed that the expressions were independent of the magnetic field. The more powerful this is, the slower need the armature run to generate the respective electromotive forces. Assuming that the transformer is supplied at constant potential at its primary terminals, and that the internal resistance of the secondary winding is small, it will be self-regulating, giving a constant potential at its secondary terminals quite irrespective of the variations of its speed with the load.

In yet one other respect does the action of the motorgenerator resemble the alternating transformer: when supplied at constant potential it is almost exactly self-regulating in respect of its automatic action in adjusting the amount of the inflowing primary current, in proportion to the outflowing secondary current. When the secondary circuit is entirely opened, the motor part runs just so fast that the back electromotive force $\mathrm{E}_{1}$ in the primary part increases and dams back the primary current; only just so much flowing through as will suffice to drive the machine against the reactive forces of mechanical and magnetic friction.

Precisely similar relations to those traced out for motorgenerators hold good in the commuting-transformers. The reactions between the primary and secondary windings go on Phil. Mag. S. 5. Vol. 26. No. 159. Ang. 1888. 
exactly the same, whether the successive displacement in the polarity of the magnetization through the common core of the armature be accomplished by mechanically rotating it, or by electrically shifting the polarity of the surrounding fieldmagnet in a rotatory fashion. With equal weights of copper in the primary and secondary coils of the armature part, the effect of mutual induction will here also be approximately to double the internal resistance and to neutralize the selfinduction of the secondary winding.

XIX. The Contact-Angle of Liquids and Solids. $B y$ W. F. Magie, Ph.D.*

\section{Introduction.}

GAUSS, in his discussion of the theory of Capillarity, U demonstrates that the surface of any liquid in contact with a solid will make with the solid a definite angle at the line of contact $\dagger$. The assumptions at the foundation of his theory are the same as those made by Laplace-that the force between two molecules diminishes very rapidly as the distance between them increases, and that, nevertheless, the radius of molecular force is such as to include within it a large number of molecules. The expression for the contact-angle $A$ (that is, the angle between the normal to the solid surface and the normal to the liquid surface at the line of contact, or, more strictly, at a distance from the solid equal to the radius of molecular force) is $\cos A=\frac{2 \beta^{2}-\alpha^{2}}{\alpha^{2}}$. The quantities $\alpha^{2}$ and $\beta^{2}$ are constants for each liquid and solid, depending respectively upon the forces between the elements of the liquid and those between the elements of the liquid and the solid. Upon the hypothesis that the laws of these forces as functions of the distance between the elements are the same, or that the ratio of the functions $f(x)$ and $\mathrm{F}(x)$ representing them is independent of the value of $x$, these constants $\alpha^{2}$ and $\beta^{2}$ are proportional to the forces upon which they depend. Upon this hypothesis, then, there will be an obtuse contact-angle when the force between two liquid elements is greater than twice that between a liquid and a solid element. When the force between two liquid elements is less than twice and more than once the force between a liquid and a solid element there will be an acute contact-angle, which is not zero. Such an

* Communicated by the Author.

† Gauss, Fig. Fluid., Werke, vol, v. p. 69. 